\title{
Spectroscopic and Morphological Studies of Metal-Organic and Metal-Free Dyes onto Titania Films for Dye-Sensitized Solar Cells
}

\author{
Gabriella Di Carlo, ${ }^{1}$ Daniela Caschera, ${ }^{1}$ Roberta G. Toro, ${ }^{1}$ Cristina Riccucci, ${ }^{1}$ \\ Gabriel M. Ingo, ${ }^{1}$ Giuseppina Padeletti, ${ }^{1}$ Luisa De Marco, ${ }^{2}$ Giuseppe Gigli, ${ }^{2,3,4}$ \\ Giovanna Pennesi, ${ }^{5}$ Gloria Zanotti, ${ }^{5}$ Anna M. Paoletti, ${ }^{5}$ and Nicola Angelini ${ }^{5}$ \\ ${ }^{1}$ Institute for the Study of Nanostructured Materials (ISMN), CNR, Via Salaria km 29300, Monterotondo, 00015 Rome, Italy \\ ${ }^{2}$ Center for Biomolecular Nanotechnologies (CBN), Fondazione Istituto Italiano di Tecnologia, \\ Energy Platform Via Barsanti, Arnesano, 73010 Lecce, Italy \\ ${ }^{3}$ National Nanotechnology Laboratory (NNL), CNR Istituto Nanoscienze, c/o Distretto Tecnologico, Via Arnesano km 5, \\ 73100 Lecce, Italy \\ ${ }^{4}$ Department of Mathematics and Physics "E. De Giorgi", University of Salento, Via per Arnesano, 73100 Lecce, Italy \\ ${ }^{5}$ Institute of Structure of Matter (ISM), CNR, Via Salaria km 29300, Monterotondo, 00015 Rome, Italy
}

Correspondence should be addressed to Gabriella Di Carlo; gabriella.dicarlo@ismn.cnr.it and Nicola Angelini; nicola.angelini@ism.cnr.it

Received 13 July 2013; Accepted 27 August 2013

Academic Editor: Giuseppe Calogero

Copyright (C) 2013 Gabriella Di Carlo et al. This is an open access article distributed under the Creative Commons Attribution License, which permits unrestricted use, distribution, and reproduction in any medium, provided the original work is properly cited.

We have investigated the spectroscopic behavior of three different sensitizers adsorbed onto titania thin films in order to gain information both on the electron transfer process from dye to titania and on the anchorage of the chromophore onto the semiconductor. We have examined by UV-Vis and fluorescence spectroscopy the widely used ruthenium complex cisdi(thiocyanato)bis (2,2' -bipyridyl-4, $4^{\prime}$-dicarboxylato)ruthenium(II) (N719), the more recently developed organic molecular 3-(5(4-(diphenylamino)styryl)thiophen-2-yl)-2-cyanoacrylic acid (D5), and a push-pull zinc phthalocyanine sensitizer (ZnPc). Three type of titania films with different morphology, characterized by SEM and FT-IR measurement, were considered: a mesoporous transparent film deposited by spin-coating (TiMS), a semiopaque film deposited by doctor-blade from mesoporous titania (TiMS_DB) and a semiopaque film deposited by doctor-blade form commercial P25 titania (P25_DB). The use of TiMS is responsible for the adsorption of a higher amount of dye since the mesoporous structure allows increasing the interfacial area between dye and titania. Moreover, the fluorescence emission peak is weaker when the sensitizers are adsorbed onto TiMS. These findings suggest that mesostructured films could be considered the most promising substrates to realize photoanodes with a fast electron transfer process.

\section{Introduction}

Dye-sensitized solar cells (DSSCs) are receiving increasing attention during the last decades since they are considered a viable and cost-effective technology for the conversion of sunlight into electricity [1-3]. In these devices, metalorganic or metal-free dyes are chemically adsorbed onto a wide band gap semiconductor oxide [1-8]. The working principle of a DSSCs system is based on the photochemical and photophysical processes: upon photoexcitation of the dyes by visible light, electrons are excited from the ground state of the dye to its excited state, and then their injection can occur from the excited dye into the conduction band of the semiconductor.

To achieve a high power conversion efficiency, the electron injection process must be certain and faster than 
the competing fluorescence and nonradiative processes. This photoinduced electron transfer leads to the production of photocurrent and consequently it is crucial to the device efficiency [1-3].

In DSSCs, the sensitizer is one of the critical components as it absorbs sunlight and induces the charge separation process. In order to enhance power conversion efficiencies of DSSCs, it is imperative to improve the light-harvesting ability of the dyes. It is also fundamental to investigate and to optimize the dye-substrate interaction that is involved in the electron transfer process [9].

Ruthenium sensitizers, such as cis-di(thiocyanato)bis $\left[2,2^{\prime}\right.$-bipyridyl- $4,4^{\prime}$-dicarboxylic acid] ruthenium (II) (N3) or its bistetrabutylammonium (TBA) salt counterpart (N719), in combination with thick titania films (>12-15 mm) have shown solar-to-electric power conversion efficiencies up to $11 \%[2,10]$. Several groups have also developed metal-free organic sensitizers, that are less expensive, and obtained efficiencies in the range of $4-8 \%$ [11-15]. Interest has been recently devoted to the design of sensitizers that are able to absorb at the near infrared region, by extending the spectral range for the photocurrent generation with respect to $\mathrm{Ru}$-complexes. Porphyrins and phthalocyanines are being currently considered to this specific aim, and meaningful results have been achieved [16-18].

The critical factors that influence sensitization are the excited-state redox potential, which should match the energy of the conduction band edge of the semiconductor substrate, the light-harvesting ability, and the electron transfer process that is influenced by the electronic coupling between the lowest unoccupied molecular orbital (LUMO) of the dye and the $\mathrm{TiO}_{2}$ conduction band. One of the major factors for low conversion efficiency of many organic dyes in the DSSC is the formation of dye aggregates on the semiconductor surface. Therefore, to obtain optimal performance, aggregation of dyes needs to be avoided by promoting the chemisorption onto the substrate and by increasing the surface area of the semiconductor oxide. High surface area substrates can also promote the adsorption of a larger amount of dye molecules enhancing the light-harvesting efficiency. However, in order to improve the power conversion efficiency of photoanodes for DSSCs, it is necessary to achieve both optimal morphological properties and fast electron transport [19-22].

To gain information about the photoinduced electron transfer process from the sensitizers to the semiconductors and indications about the linkage between dye and substrate, the study of the spectroscopic features of chromophores onto the semiconductor is of crucial importance. Absorption and steady-state emission spectral features can give information on the dye interaction with the substrate, since they are influenced by the chemical environment of the sensitizers and hence, it is expected that the structural and chemical nature of the sensitizers and the structural properties of titania substrates have a key role in determining the final spectral features of the chromophore. Moreover, time-resolved fluorescence decay can provide insights into the electron injection process, since it is competitive with fluorescence relaxation. Electron injection is found to generally occur with a time much shorter than the excited-state lifetime of typical dyes, therefore time-resolved fluorescence decay studies are very useful to understand these dynamic photoinduced processes.

Herein, for the purpose of comparison, three different dyes were examined: the widely used inorganic ruthenium complex cis-di(thiocyanato) bis $\left(2,2^{\prime}\right.$-bipyridyl- $4,4^{\prime}$-dicarboxylato)ruthenium(II) (N719), the more recently developed organic molecular 3-(5-(4-(diphenylamino) styryl)thiophen2-yl)-2-cyanoacrylic acid (D5) [15], and the push-pull zinc phthalocyanine sensitizer $(\mathrm{ZnPc})$ [23]. The dyes were adsorbed onto three types of thin film titania substrates: mesoporous transparent titania deposited by spin-coating (TiMS), mesoporous titania deposited by doctor-blade (TiMS_DB) and commercial P25 titania deposited by doctor-blade (P25_DB). Titania films were characterized by scanning electron microscopy (SEM) and by Fourier transform infrared (FT-IR) spectroscopy, whereas the dyesensitized films were studied by UV-Vis and fluorescence spectroscopy.

\section{Experimental Section}

\subsection{Preparation of Titania Thin Films}

2.1.1. Transparent and Mesoporous Films. Mesoporous titania films were synthesized using the P123 block copolymer as template in order to obtain an ordered porous structure with a controlled geometry. The titania precursor solutions were prepared according to the procedures described in the literature using pluronic surfactant [24].

In a typical synthesis, $1.4 \mathrm{~mL}$ of concentrated $\mathrm{HCl}$ were slowly added to $2.1 \mathrm{~g}$ of titanium(IV) ethoxide at room temperature. In another flask, $0.65 \mathrm{~g}$ of P123 were dissolved in $6 \mathrm{~g}$ of 1-butanol and subsequently added to the titanium solution. The system was kept under stirring at room temperature for 3 hours. The as-prepared solution of titania precursor was deposited on FTO conducting glass substrates (Dyesol, $15 \Omega \mathrm{sq}^{-1}$ ) by spin-coating at $2400 \mathrm{rpm}$. After aging at $25^{\circ} \mathrm{C}$ for 2 days, optically uniform and transparent films were obtained. These films were calcined at 350 for 30 minutes using a ramp rate of $1^{\circ} \mathrm{C} / \mathrm{min}$ to remove the template and the residual organic precursors. $\mathrm{TiO}_{2}$ electrodes were obtained by deposition of three layers with a final calcination at $350^{\circ} \mathrm{C}$ for 2 hours and were labeled as TiMS (Table 1). The resulting mesoscopic oxide film was around $1 \mu \mathrm{m}$ thick and transparent.

2.1.2. Semiopaque Films from Mesoporous Titania. Mesoporous titania powder was prepared from the solution of titanium (IV) ethoxide and P123 described above after aging at $25^{\circ} \mathrm{C}$ for 5 days and subsequent calcination at $350^{\circ} \mathrm{C}$ for 4 hours using a ramp rate of $1^{\circ} \mathrm{C} / \mathrm{min}$, according to a recently published procedure [25].

Titania films were prepared from mesoporous titania powder by using the doctor-blade technique, according to a procedure described elsewhere [26]. Dried powder was dispersed in ethanol (EtOH), treated with ultrasonic bath for $30 \mathrm{~min}$, then stirred at $50^{\circ} \mathrm{C}$ for $1 \mathrm{~h}$. This procedure was repeated three times in order to obtain a homogeneous and 
TABLE 1: Details about the preparation of titania films.

\begin{tabular}{lcc}
\hline Sample & $\mathrm{TiO}_{2}$ source & $\begin{array}{c}\text { Deposition } \\
\text { technique }\end{array}$ \\
\hline TiMS & $\begin{array}{c}\text { Alcoholic solution of titanium(IV) } \\
\text { ethoxide and P123 }\end{array}$ & Spin-coating \\
TiMS_DB & $\begin{array}{c}\text { Mesoporous titania powder prepared } \\
\text { from alcoholic solution of } \\
\text { titanium(IV) ethoxide and P123 }\end{array}$ & Doctor-blade \\
P25_DB & Commercial P25 titania powder & Doctor-blade \\
\hline
\end{tabular}

opalescent colloidal suspension. The latter was mixed with ethylcellulose (5-15 $\mathrm{mPa} * \mathrm{~s})$ previously dissolved in ethanol $(10 \% \mathrm{w} / \mathrm{w})$ and stirred again at $50^{\circ} \mathrm{C}$ overnight. Terpineol was added, and the resulting mixture was further stirred for $6 \mathrm{~h}$. Finally ethanol was removed by a rotary evaporator to obtain pastes suitable for doctor-blade deposition. The paste had the following weight percentage composition: $\mathrm{TiO}_{2}: 4 \%$; ethylcellulose: $2 \%$; terpineol: $94 \%$. The so-obtained titania paste was deposited on the FTO conducting glass (Dyesol, $\left.15 \Omega \mathrm{sq}^{-1}\right)$. Two edges of the FTO glass plate were covered with a layer of adhesive tape (3M Magic) to control the thickness of the film; successively the titania paste was spread uniformly on the substrate by sliding a glass rod along the tape spacer. After drying the coated plates were sintered in air for $1 \mathrm{~h}$ at $450^{\circ} \mathrm{C}$ and labelled as TiMS_DB (Table 1). The resulting mesoscopic oxide film was around $1 \mu \mathrm{m}$ thick and semiopaque.

\subsubsection{Semiopaque Films from Commercial Titania. Reference} titania films were prepared from commercial P25 titania powder by using the doctor-blade technique, according to a procedure described elsewhere [26]. Briefly, acetic acid, water and ethanol were added drop by drop into a mortar containing P25 titanium dioxide nanoparticles (provided by Evonik Degussa). The $\mathrm{TiO}_{2}$ dispersion was transferred with excess of ethanol into a beaker for stirring a sonication steps; then anhydrous terpineol and ethyl cellulose (previously dissolved in ethanol) were added. After further stirring and sonication steps the dispersion was concentrated by rotary evaporator. The final colloidal paste was characterized by the following composition (wt/wt): $5 \% \mathrm{TiO}_{2}, 0.5 \%$ acetic acid, $2.5 \%$ ethylcellulose, $87 \%$ terpineol, and $5 \%$ ethanol. The soobtained titania paste was deposited on the FTO conducting glass (Dyesol, $15 \Omega \mathrm{sq}^{-1}$ ). Two edges of the FTO glass plate were covered with a layer of adhesive tape (3 M Magic) to control the thickness of the film; successively the titania paste was spread uniformly on the substrate by sliding a glass rod along the tape spacer. After drying, the coated plates were sintered in air for $1 \mathrm{~h}$ at $450^{\circ} \mathrm{C}$ and labelled as P25_DB (Table 1). The resulting mesoscopic oxide film was around $1 \mu \mathrm{m}$ thick and semiopaque.

2.2. Adsorption of Dyes onto Titania Films. The dye-sensitized films were prepared using a $0.2 \mathrm{mM}$ N719 solution (ditetrabutylammonium cis-bis(isothiocyanato) bis(2,2' -bipyridyl$4,4^{\prime}$-dicarboxylato)ruthenium(II)), which was obtained by dissolving the dye in a mixture of acetonitrile and tert-butyl alcohol (1:1 volume ratio). The titania films were immersed into the N719 solution overnight at room temperature. After that all the dyed films were washed with acetonitrile and stored in the dark.

A similar procedure was used for the adsorption of D5 and $\mathrm{ZnPc}$. The D5 dye was dissolved in acetonitrile to obtain a dye concentration of $0.2 \mathrm{mM}$, whereas the solution of $\mathrm{ZnPc}$ was obtained by dissolution in ethanol $(0.89 \mathrm{mg}$ of dye in $10 \mathrm{~mL}$ of ethanol).

2.3. Characterization. UV-vis spectra of the films were collected in the wavelength range $300-870 \mathrm{~nm}$ using a double beam spectrophotometer V-660 (Jasco) equipped with an integrated sphere. The absorbance of the dye solution was measured using a quartz cell of thickness $1 \mathrm{~cm}$. The absorbance of dye- $\mathrm{TiO}_{2}$ systems was recorded using $60 \mathrm{~mm}$ integrated sphere.

Steady-state fluorescence spectra for dyes solution and dyes- $\mathrm{TiO}_{2}$ films were recorded in a Jobin Yvon Fluorolog3 spectrofluorometer, using grids of $5 \mathrm{~nm}$ for the excitation and $5 \mathrm{~nm}$ for emission.

Time-resolved fluorescence measurements were carried out by a time-correlated single-photon-counting (TCSPC) system (Horiba-Jobin Yvon). Time-resolved measurements are carried on exciting the samples using a $405 \mathrm{~nm}$ pulsed laser diode and collecting the emission decay at the corresponding maximum emission wavelength for the specific analysed dye. The fluorescence decay profiles were analysed through decay analysis software (DAS6a HORIBA Scientific) to a multiexponential decay equation. The quality of the fits was checked by examining the residual distribution and the $\chi^{2}$ value.

Both steady-state and time-resolved fluorescence measurements of thin films $\mathrm{TiO}_{2}$ systems were collected in rightangle (RA) configuration with a tilt angle of $30^{\circ}$ to minimize substrate scattering effects.

Fourier transform infrared (FT-IR) spectra were collected using a Jasco 4100 FT/IR spectrophotometer equipped with an attenuated total reflectance (ATR) unit. The samples for the analysis were prepared through preliminary drying at $120^{\circ} \mathrm{C}$.

FE-SEM characterizations were carried out with a highbrilliance LEO 1530 field emission scanning electron microscope apparatus equipped with an INCA 450 energydispersive X-ray spectrometer (EDS) and a four-sector backscattered electron detector (BSD). Before the analysis, the surfaces were coated with a thin layer of carbon in order to avoid charging effects. The carbon coating was deposited by using an Emitech sputter coater K550 unit, a K 250 carboncoating attachment, and a carbon cord at a pressure of $1 \times$ $10^{-2}$ mbar in order to produce a carbon film with a thickness of a few nanometers.

\section{Results and Discussion}

The spectral properties of different dyes have been compared in order to investigate the electron transfer process from the 


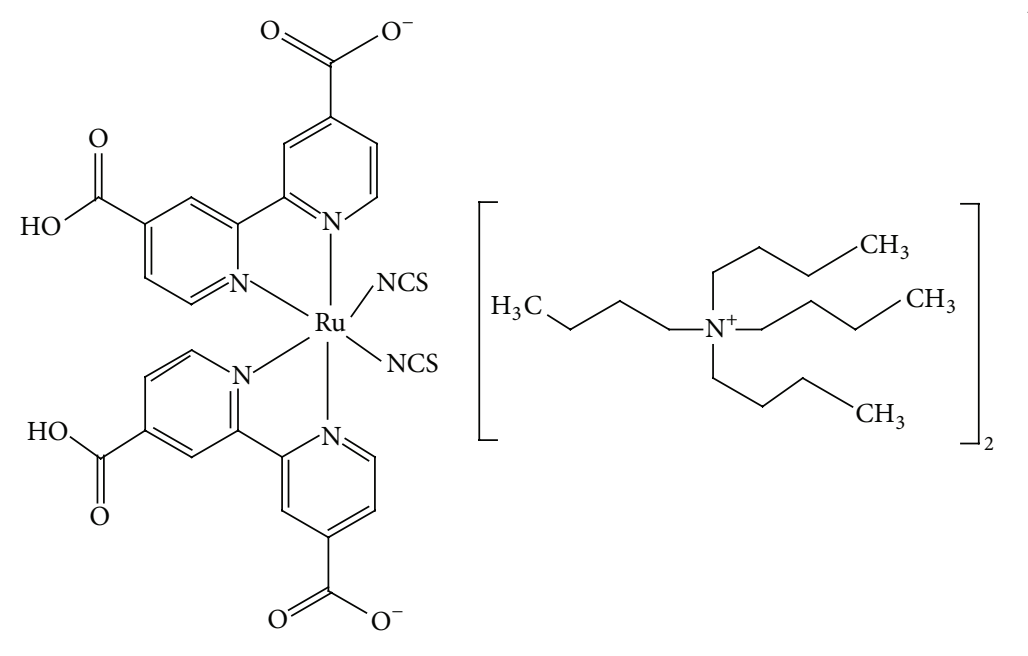<smiles>N#C/C(=C\c1ccc(/C=C/c2ccc(N(c3ccccc3)c3ccccc3)cc2)s1)C(=O)O</smiles><smiles>C/C=C\C=C(/C)C#Cc1ccc(C(=O)O)cc1</smiles>

$\mathrm{ZnPc}$

FIgure 1: Chemical structure of the dyes: N719, D5, and ZnPc.

dye to the conduction band of titania films that is responsible for the production of photocurrent in DSSCs. Metalorganic and metal-free dyes were adsorbed onto transparent and semiopaque mesoporous titania thin films and onto a semiopaque film form commercial P25 titania. In particular, we have investigated the behaviour of a ruthenium complex (N719), an organic dye (D5), and a zinc phthalocyanine system $(\mathrm{ZnPc})$. The chemical structure of these dyes is shown in Figure 1.

All the dyes have been adsorbed onto titania films with different morphology: a mesoporous transparent film deposited by spin-coating (TiMS), a semiopaque film deposited by doctor-blade from mesoporous titania (TiMS_DB), and a semiopaque film deposited by doctorblade form commercial P25 titania (P25_DB). The preparation of the films was properly tailored in order to get thin substrates with a comparable thickness of about $1 \mu \mathrm{m}$.

3.1. FTIR Characterization. The surface functional groups of titania substrates play an important role in the chemisorption of the dyes. Indeed, the sensitizers that we are considering in this work are usually bonded to titania through their carboxylic groups, which interact with hydroxyl groups at titania surface.

ATR-FTIR measurements were used to investigate the amount of hydroxyl groups in the different titania films, and the spectra are displayed in Figure 2. Furthermore, by these analyses it is also possible to get more information on the presence of carbon species in the samples.

The ATR-FTIR spectra show similar trends, but with some significant differences. The bending vibration band of the surface hydroxyl groups is observed at about $1630 \mathrm{~cm}^{-1}$,

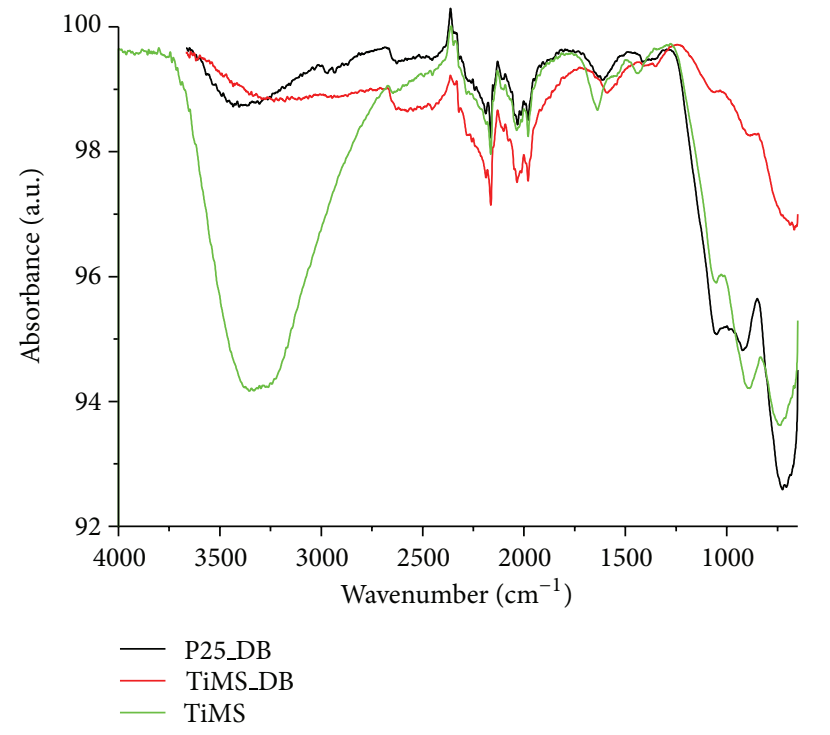

FIgUre 2: ATR-FTIR spectra of titania thin films: (a) P25_DB, (b) TiMS_DB, and (c) TiMS.

and the corresponding stretching vibration peak is located at $3200-3600 \mathrm{~cm}^{-1}[27,28]$. From these spectra, a significantly higher amount of hydroxyl groups was noticed in transparent titania thin films (TiMS). This could be attributed to the lower sinterization temperature $\left(350^{\circ} \mathrm{C}\right.$ instead of $450^{\circ} \mathrm{C}$ used for DB films) that allows preserving a high amount of hydroxyl surface groups, and it seems also reasonable to assume that it could be also related to a higher surface area. On the contrary, the film from Degussa P25 has the lowest amount of surface hydroxyl groups.

Analyzing the FTIR spectra, it can also be observed that titania films contain carbon groups. Indeed, the peaks at 
TABLE 2: Peak position of UV-Vis absorbance and fluorescence emission.

\begin{tabular}{lcc}
\hline Sample & $\lambda_{\text {Abs }}(\mathrm{nm})$ & $\lambda_{\text {Em }}(\mathrm{nm})$ \\
\hline N719 & $310,386,537$ & 728 \\
N719@P25_DB & 478 & 726 \\
N719@TiMS_DB & 474 & 719 \\
N719@TiMS & 492 & 720 \\
\hline D5 & 300,479 & 630 \\
D5@P25_DB & 468 & 605 \\
D5@TiMS_DB & 469 & 623 \\
D5@TiMS & 472 & 618 \\
\hline ZnPc & $352,613,687$ & 694 \\
ZnPc@P25_DB & 689 & 695 \\
ZnPc@TiMS_DB & 692 & 698 \\
ZnPc@TiMS & 689 & 702 \\
\hline
\end{tabular}

about $1000-1100 \mathrm{~cm}^{-1}$ suggest the presence of Ti-O-C bonds [27]. Furthermore, the peak at about $1400 \mathrm{~cm}^{-1}$ has been attributed to asymmetric bending vibrations of $\mathrm{C}-\mathrm{H}$ bonds $[27,28]$. The observation from FTIR that the films contain $\mathrm{Ti}-\mathrm{O}-\mathrm{C}$ and $\mathrm{C}-\mathrm{H}$ bonds indicates the presence of residual organic groups. The intensity of these signals for P25_DB and TiMS is comparable, whereas the residual carbon content is apparently lower for TiMS_DB film (Figure 2).

3.2. Morphological Investigation. Further insights into the structural properties of titania films were obtained through FE-SEM analysis. The micrographs of titania surface films prepared by doctor-blade (Figure 3 ) reveal that when commercial P25 was used for the formulation of the paste the photoanode surface consists of small nanoparticles with voids into the structure. By using mesoporous titania, the photoanode surface is composed of small nanoparticles and a porous structure can be observed. It is worth to notice that in TiMS_DB the surface morphology is more uniform with the presence of small pores that could increase the interface between dye and titania, whereas larger voids are not detected.

In TiMS prepared by spin-coating, the surface morphology is completely different. The films are furthermore compact, and can be observed the presence of domains with an ordered structure. The latter are mesoporous channels, which are responsible for a nanoporous structure and high surface area.

3.3. UV-Vis and Fluorescence Measurements. In order to gain information on the anchorage of the chromophore onto the semiconductor and on the electron transfer process from the dyes to titania, the spectroscopic features of the dye solutions and of the dye-sensitized titania films have been investigated.

The absorption and the steady-state fluorescence spectra of the free dye solutions and the corresponding dye-sensitized $\mathrm{TiO}_{2}$ films were recorded, and the data are summarized in Table 2.

The absorption spectra of N719 sensitized $\mathrm{TiO}_{2}$ films along with the reference spectrum of the free dye in an acetonitrile and tert-butyl alcohol solution (1:1 volume ratio) are shown in Figure 4. In particular, the UV-vis absorption spectrum of N719 solution is dominated by two broad bands at around 386 and $537 \mathrm{~nm}$, generally assigned to a Metal-toLigand Charge-Transfer (MLCT) transition in which an electron is transferred from $\mathrm{Ru}$ to one of the bipyridine ligands, and an intense UV absorption at around $310 \mathrm{~nm}$ attributed to an electronic transition between the $\pi-\pi^{*}$ orbitals of the dcbpyH ligands [29-31]. When the N719 molecules are adsorbed onto the surface of mesoporous $\mathrm{TiO}_{2}$ films, the MLCT band at $537 \mathrm{~nm}$ becomes predominant and shifts at lower wavelengths depending on the considered $\mathrm{TiO}_{2}$ system. The measured blue shifts for all the dye-sensitized $\mathrm{TiO}_{2}$ systems are reported in Table 2; as it can be seen it is higher for the N719 adsorbed onto $\mathrm{TiO}_{2}$ films obtained by doctorblade (P25 and TiMS_DB), whereas it is lower for the N719 adsorbed onto transparent $\mathrm{TiO}_{2}$ obtained by spin-coating technique (TiMS). The observed shifts in the absorption spectra are probably due to chemical interactions between the dye and the semiconductor $\mathrm{TiO}_{2}$ surface, which modify HOMO and LUMO levels of the adsorbed complexes with respect to those of the free dye. At the same time, we would like to underline the higher absorption intensity shown by the transparent N719@TiMS systems with respect to the other $\mathrm{TiO}_{2}$ systems, which may indicate that this transparent layer can adsorb more N719 molecules compared with the other $\mathrm{TiO}_{2}$ layers having the same thickness. This is also confirmed by the intense red coloration of the TiMS sample after the dye adsorption. These findings are in agreement with ATR-FTIR results previously discussed, since the most intense peaks in UV-vis spectra of dye-sensitized TiMS films is promoted by the presence of a high number of surface hydroxyl groups.

A similar trend has been also found in the case of the metal-free organic dye $\mathrm{D} 5$ adsorbed on $\mathrm{TiO}_{2}$ mesoporous systems (Table 2). Two absorption bands at $479 \mathrm{~nm}$ and $300 \mathrm{~nm}$ are visible in the Uv-Vis spectrum of dye solution; the band in the UV region corresponds to a $\pi-\pi^{*}$ transition of the conjugated molecules, whereas the band in the Vis can be assigned to an intramolecular charge-transfer state between the diphenylaniline electron donating moiety and the cyanoacetic acceptor [15]. When the dye is attached to $\mathrm{TiO}_{2}$ surface, a blue shift of the absorption maximum at $479 \mathrm{~nm}$ is found (Table 2). Also in the case of D5, the transparent TiMS thin films have the highest intense absorption band and the lowst blue shift with respect to those observed for D5@TiMS_DB and D5@P25_DB, thus indicating a higher dye uptaking.

The fluorescence measurements of N719 and D5 sensitized mesoporous $\mathrm{TiO}_{2}$ systems, reported in Figures 5 and 6 , show the characteristic fluorescence emission of the free dyes but shifted to lower wavelenghts. In the case of N719 (Figure 5), for example, upon excitation at $\lambda_{\text {ex }}=510 \mathrm{~nm}$, the solution has an emission maximum at $728 \mathrm{~nm}$, which shifts at 725, 719, and 720 nm for N719@P25_DB, N719@TiMS_DB, and N719@TiMS, respectively. In analogy, the D5 sensitized $\mathrm{TiO}_{2}$ systems have a blue shift in the emission spectra (Figure 6) that depend on the $\mathrm{TiO}_{2}$ system. More interesting, if we consider the intensity of the emission band for both of the two sets of sample we observe that they decrease following 


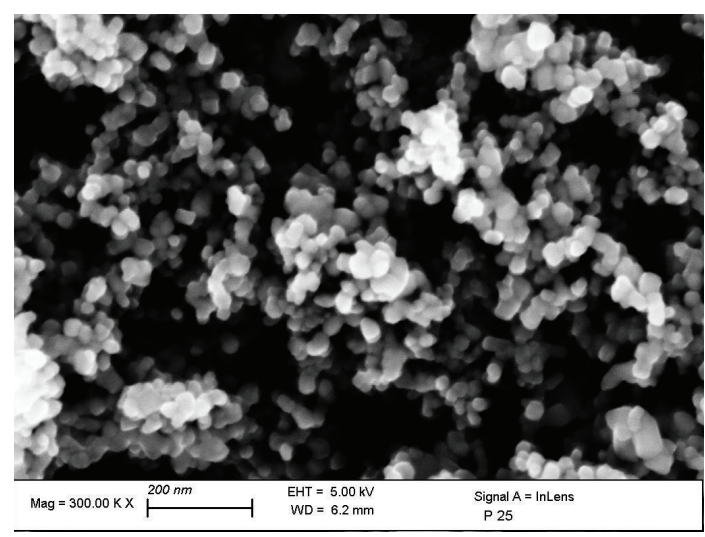

(a)

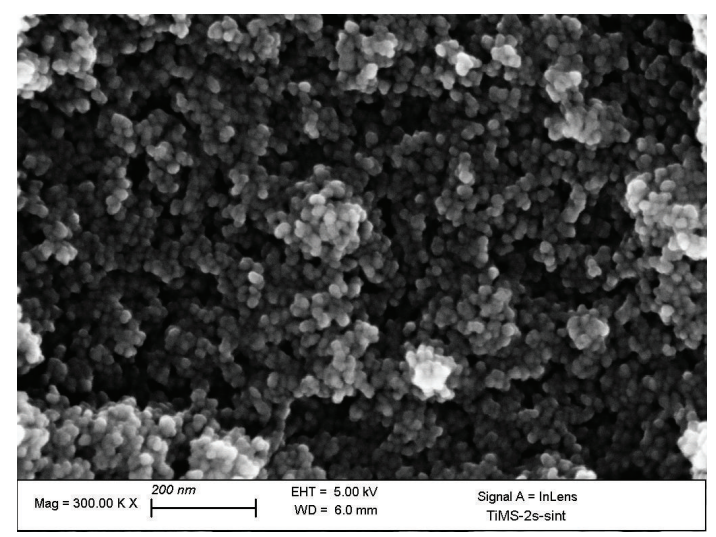

(b)

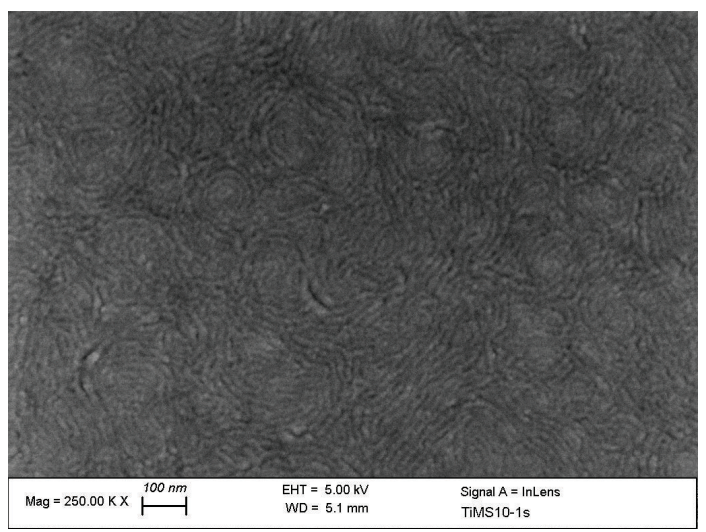

(c)

FIGURE 3: FE-SEM images of surface titania films: (a) P25_DB, (b) TiMS_DB, and (c) TiMS.

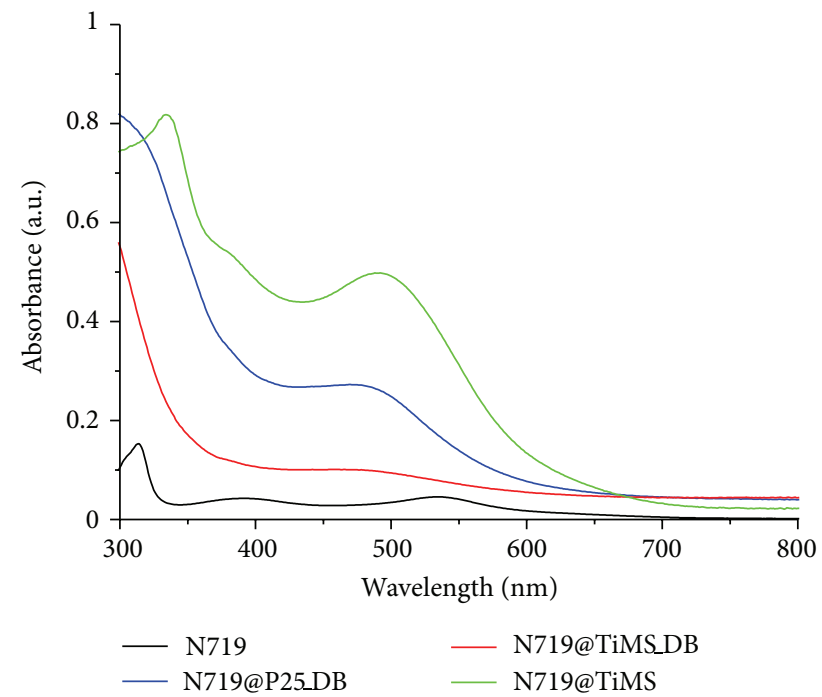

FIGURE 4: Uv-Vis absorbance for N719 solution and N719 sensitised $\mathrm{TiO}_{2}$ systems.

the order P25_DB > TiMS_DB > TiMS. The reduction in the emission intensity is thus more evident in the case of transparent mesoporous $\mathrm{TiO}_{2}$ layer, and we hypothesized that it can be associated in first approximation to a better and more

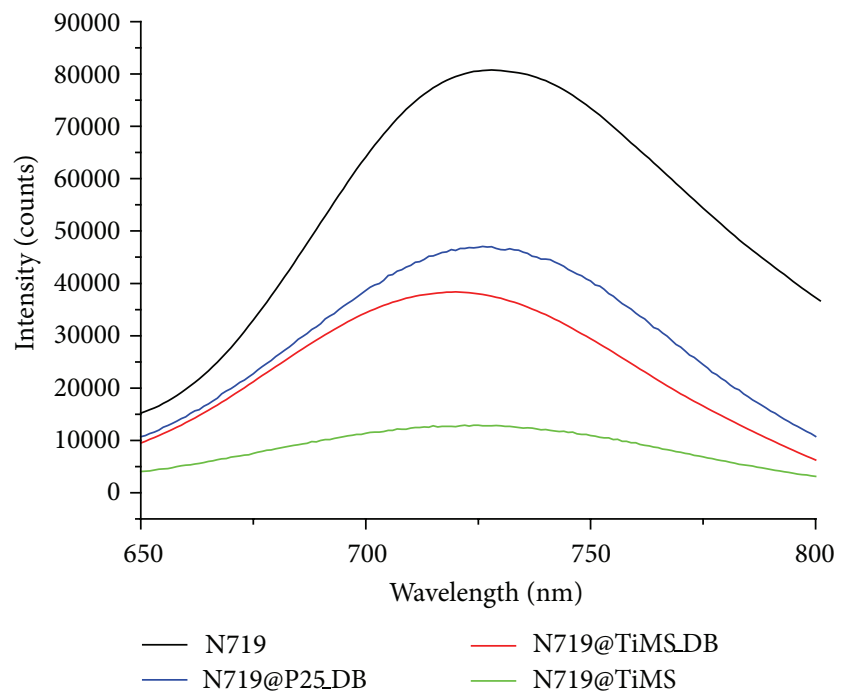

FIGURE 5: Steady-state fluorescence emission for N719 solution and N719 sensitised $\mathrm{TiO}_{2}$ systems.

efficient electron injection process from the excited state of the dye to the conduction band of the semiconductor.

The UV-Vis absorption spectra of the compound $\mathrm{ZnPc}$ in $\mathrm{EtOH}$ and on mesoporous $\mathrm{TiO}_{2}$ films are displayed in 


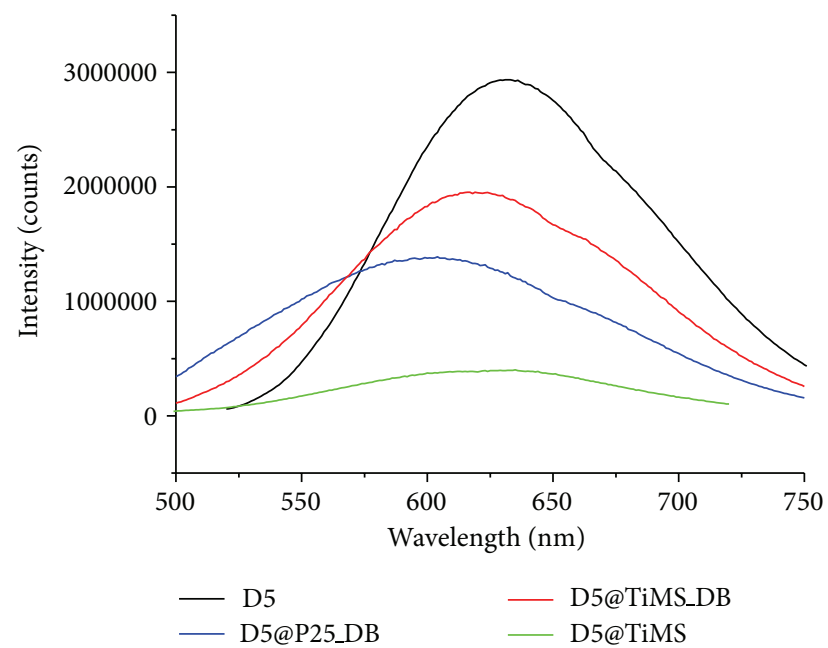

FIGURE 6: Steady-state fluorescence emission for D5 solution and D5 sensitised $\mathrm{TiO}_{2}$ systems. The emission intensity values for D5 sensitised $\mathrm{TiO}_{2}$ systems are multiplied by a factor 5 .

Figure 7. The UV-Vis absorption spectrum of ZnPc exhibits an intense Soret band $(300-400 \mathrm{~nm})$ due to the $\pi-\pi^{*}$ transition with charge-transfer character and a strong Q band centered at $687 \mathrm{~nm}$ [32]. In addition, compared with the solution, the zinc phthalocyanine derivative on mesoporous $\mathrm{TiO}_{2}$ films show broader absorption spectra extended to $800 \mathrm{~nm}$, suggesting the formation of aggregate on the surface of the semiconductor [33]. The absorption spectra of the phthalocyanine adsorbed onto $\mathrm{TiO}_{2}$ systems exhibit a small red shift (Table 2) that may be due to the presence of carboxylic protons of phthalocyanine, which, upon adsorption on $\mathrm{TiO}_{2}$, release the proton and bind to $\mathrm{Ti}^{4+}$ centres. $\mathrm{The}^{4+}$ sites act as electron withdrawing and produce the observed red shift in the absorption bands [34].

Figure 8 shows the steady-state fluorescence emission spectra $\left(\lambda_{\text {ex }}=400 \mathrm{~nm}\right)$ of $\mathrm{ZnPc}$ solution: the typical phthalocyanine emission band centred around $700 \mathrm{~nm}$ is easily visible [35]. The ZnPc@P25_DB, ZnPc@TiMS_DB, and ZnPc@TiMS exhibit a strong Q band emission peak at $695 \mathrm{~nm}, 698 \mathrm{~nm}$, and $702 \mathrm{~nm}$, respectively. In analogy to the other two dyes, when $\mathrm{ZnPc}$ is adsorbed onto the $\mathrm{TiO}_{2}$ layers, a net decrease in the emission intensity can be observed, thus suggesting the possibility of an electron injection process.

Time-correlated single-photon counting (TCSPC) measurements are performed to obtain information about the decay times of the relaxed excited state at $S_{1}$ of the dye interacting with the semiconductor materials. As reported by several studies $[18,23,36,37]$, TCSPC measurements can be useful to evaluate the photoelectron injection dynamics in dye-sensitized semiconductor films. In Figure 9 the timeresolved emission kinetics for the three dyes in solution and the correspondent dye sensitised $\mathrm{TiO}_{2}$ systems are shown. In particular, the emission decay measurements are collected at $\lambda_{\mathrm{em}}=730 \mathrm{~nm}$ (Figure 9(a)) for N719, at $\lambda_{\mathrm{em}}=$ $640 \mathrm{~nm}$ (Figure 9(b)) for D5, and at $\lambda_{\text {ex }}=700 \mathrm{~nm}$ for ZnPc (Figure 9(c)).

Fluorescence emission decay curves of the N719 solution have been deconvoluted by a biexponential function, while

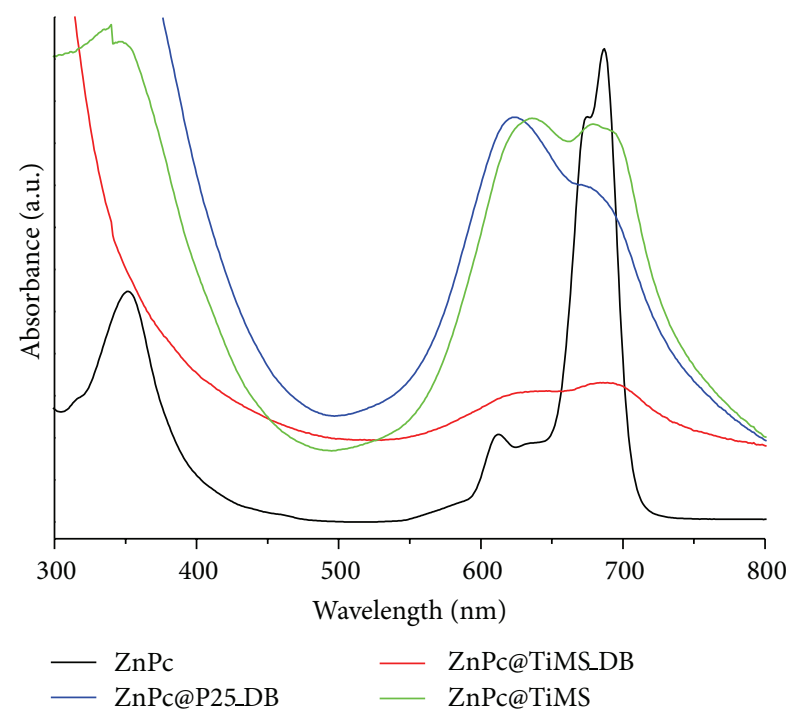

FIgURE 7: Uv-Vis absorbance for ZnPc solution and ZnPc sensitised $\mathrm{TiO}_{2}$ systems.

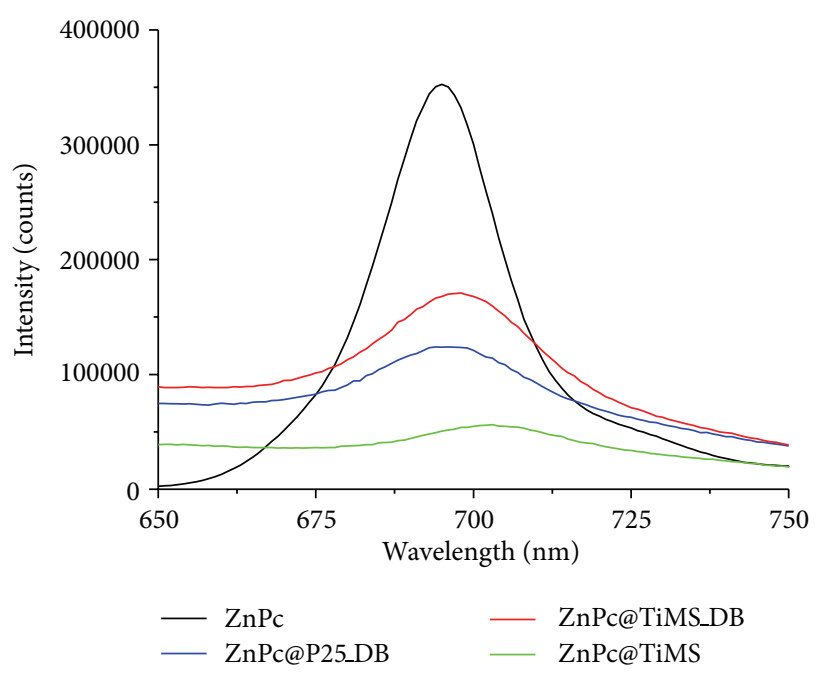

FIGURE 8: Steady-state fluorescence emission for ZnPc solution and $\mathrm{ZnPc}$ sensitised $\mathrm{TiO}_{2}$ systems. The emission intensity values for ZnPc5 sensitised $\mathrm{TiO}_{2}$ systems are multiplied by a factor 5 .

for N719 interacting with different $\mathrm{TiO}_{2}$ based films, the decays have a more complex behaviour and need a three component exponential function. The results shown in Table 3 reveal that for dye solution the most significative time value $\left(\tau_{1}\right)$ is about $3 \mathrm{~ns}\left(A_{1}=93 \%\right)$ and a little percent of molecules decay with a time of $\tau_{2}=27.7 \mathrm{~ns}\left(A_{2}=7 \%\right)$. The longer decay is comparable with time decay reported in the literature for N719 systems [38], while the shorter excited-state lifetime indicates an enhancing of the nonradiative deactivation channels, probably due to the presence of protons on carboxyl groups [39]. The $\tau_{1}=3 \mathrm{~ns}$ value appears to be retained in $\mathrm{N} 719-\mathrm{TiO}_{2}$ systems, but the corresponding amplitude $\left(A_{1}\right)$ decreases from $93 \%$ in solution to $30 \%$ in solid state. Also the longest time decay in solution $\left(\tau_{2}=27.7 \mathrm{~ns}\right)$ is preserved when the dye is adsorbed on $\mathrm{TiO}_{2}$ surface, but this value is lower 


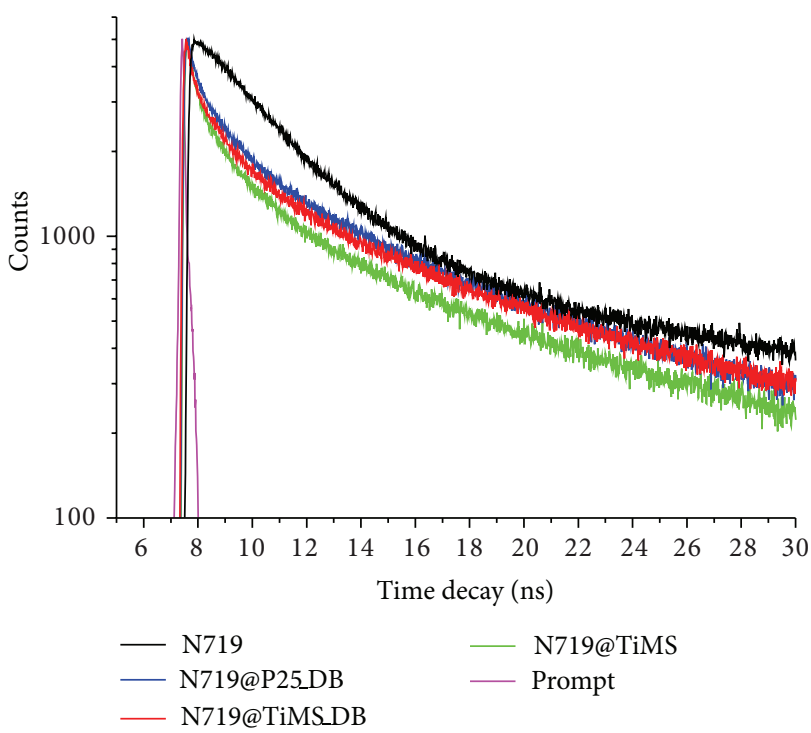

(a)

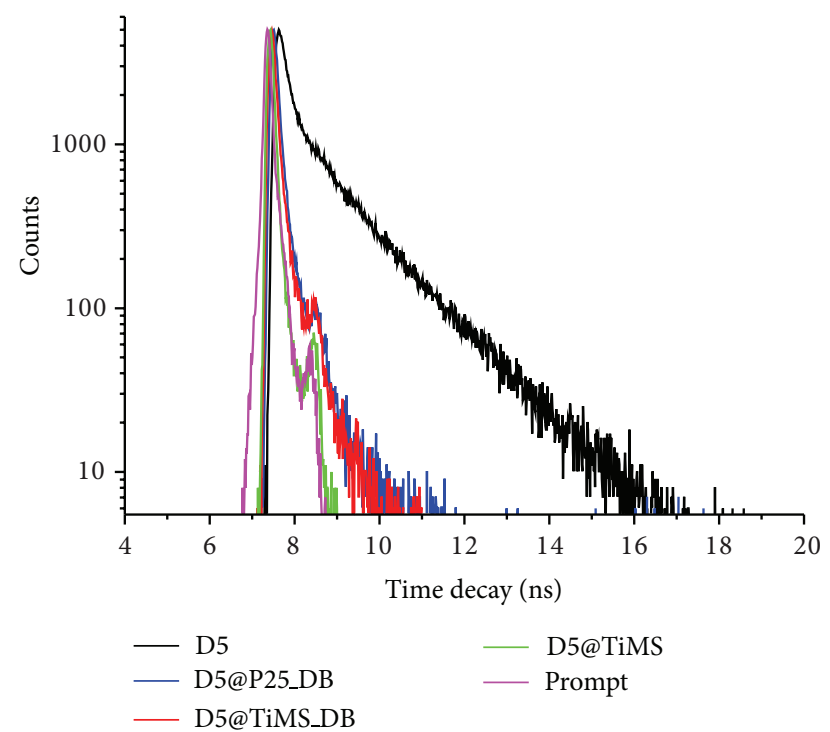

(b)

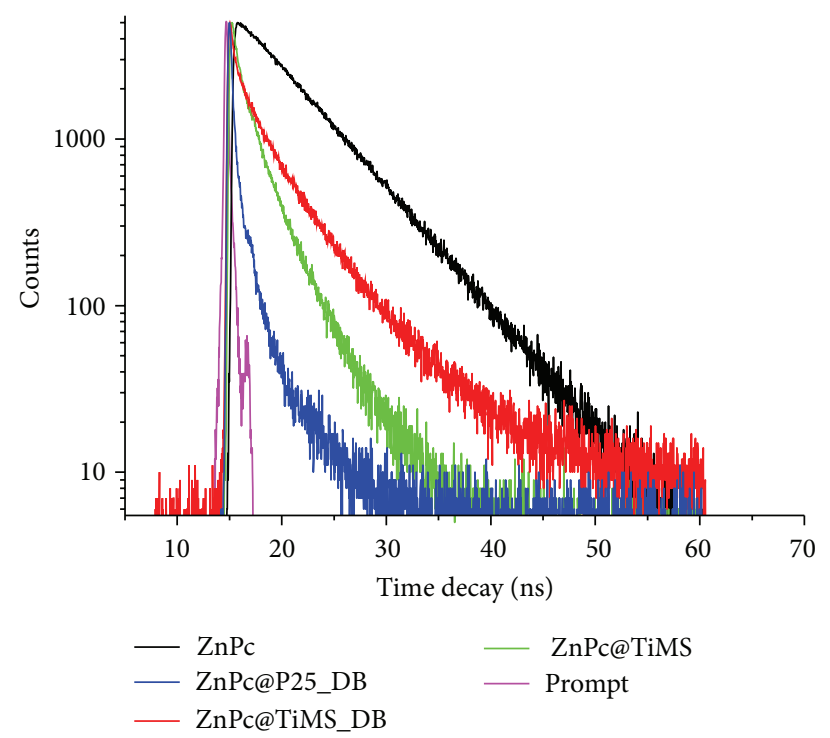

(c)

Figure 9: Fluorescence kinetics of (a) N719 solution and N719 sensitised $\mathrm{TiO}_{2}$ systems, (b) D5 solution and D5 sensitised TiO 2 systems, and (c) $\mathrm{ZnPc}$ solution and $\mathrm{ZnPc}$ sensitised $\mathrm{TiO}_{2}$ systems.

$\left(\tau_{2}=15 \mathrm{~ns}\right.$ in solid state) because dye molecules are now closer to each other than in solution, and this results in the quenching phenomena. In addition, a third shorter time appears (0.56 ns for N719@P25_DB, 0.41 ns for N719@TiMS_DB and $0.36 \mathrm{~ns}$ for N719@TiMS) that can be related to the electron transfer process from the excited state of the dye to the conduction band of the semiconductor.

Lifetime of D5 dye in solution is analysed by a three exponential component function, and the result of $0.14 \mathrm{~ns}$, associated with the most significative amplitude $\left(A_{1}=80 \%\right)$, presents a good agreement with analogous systems [40]. However, for D5 sensitised $\mathrm{TiO}_{2}$ systems the resolution of the TCSPC setup does not allow for resolving numerically the changes in lifetime. They are all sub $0.01 \mathrm{~ns}$, a time close to the time response of the detector. Nevertheless, just from a qualitatively point of view, it is interesting to observe that D5@TiMS system seems to have the sharpest decay profile with respect to D5@TiMS_DB and D5@P25_DB. The better quenching effect could be related to a different dye$\mathrm{TiO}_{2}$ interaction that could promote electron injection in semiconductor bands.

In the case of $\mathrm{ZnPc}$ solution, the fluorescence emission decay exhibits a monoexponential behaviour with a lifetime of $3 \mathrm{~ns}$, comparable for values reported in the literature for unsubstituted phthalocyanine systems $[18,41]$.

$\mathrm{ZnPc}$ sensitised $\mathrm{TiO}_{2}$ systems fluorescence emission decays, instead, are analysed using a three component exponential function and the results are summarized in Table 3. 
TABLE 3: Lifetime decay of dye- $-\mathrm{TiO}_{2}$ systems.

\begin{tabular}{lccccccc}
\hline Sample & $\tau_{1}(\mathrm{~ns})$ & $\tau_{2}(\mathrm{~ns})$ & $\tau_{3}(\mathrm{~ns})$ & $A_{1}(\%)$ & $A_{2}(\%)$ & $A_{3}(\%)$ & $\chi^{2}$ \\
\hline N719 & 2.89 & 27.7 & - & 93 & 7 & - & 1.2 \\
N719@P25_DB & 3.44 & 15.8 & 0.56 & 32 & 20 & 48 & 1.2 \\
N719@TiMS_DB & 2.74 & 14.5 & 0.41 & 33 & 20 & 47 & 1.2 \\
N719@TiMS & 2.60 & 15.6 & 0.36 & 32 & 15 & 53 & 1.2 \\
\hline D5 & 0.14 & 0.63 & 1.61 & 80 & 9 & 11 & 1.0 \\
D5@P25_DB & $<0.01$ & & & - & & & - \\
D5@TiMS_DB & $<0.01$ & & & - & & & - \\
D5@TiMS & $<0.01$ & & & - & & & - \\
\hline ZnPc & 3 & & & & & & 1.2 \\
ZnPc@P25_DB & 2.05 & 0.48 & 0.05 & 24 & 29 & 47 & 1.3 \\
ZnPc@TiMS_DB & 2.46 & 0.87 & 0.13 & 21 & 23 & 56 & 1.1 \\
ZnPc@TiMS & 1.87 & 0.78 & 0.11 & 10 & 33 & 57 & 1.2 \\
\hline
\end{tabular}

From the fitting results, the $\tau_{1}$ component is preserved in solid state systems, even if the molecule population associated to this decay mechanism decreases to $10-20 \%$. The component $\tau_{2}$, observable only in solid state systems, can be associated to a quenching effect with a mechanism similar to the behavior of J aggregates in solution [42]. The faster time decay component in dye- $\mathrm{TiO}_{2}$ system $\left(\tau_{3}\right)$ could be, in principle, indicative of an efficient injection occurring at the interface between dye molecules and semiconductor surface. Mesoporous $\mathrm{TiO}_{2}$ systems present $\tau_{3}$ decay very similar in value $(0.13 \mathrm{~ns}$ for ZnPc@TiMS_DB and $0.11 \mathrm{~ns}$ for ZnPc@TIMS), while ZnPc@P25_DB shows a quite lower $\tau_{3}$ component, about $0.05 \mathrm{~ns}$.

The two observed fast time decays $\tau_{2}$ and $\tau_{3}$ in dyes$\mathrm{TiO}_{2}$ systems could be also attributable to a contemporary presence of different injection processes; due to different possible configurations of $\mathrm{ZnPc}$ molecules when they are interacting with $\mathrm{TiO}_{2}$ surface, one is more favourable than the other.

\section{Conclusions}

The steady-state measurements and fluorescence emission decay of the dye-sensitized titania films suggest that the transparent mesoporous titania film (TiMS) could be responsible for a more efficient electronic injection when N719 and D5 are used as sensitizers. Indeed, the emission peak of these dyes has a lower intensity onto TiMS, and a faster time decay was observed. In the case of $\mathrm{ZnPc}$, the fluorescence emission decay is faster if the dye is adsorbed onto P25_DB. Probably the formation of dye aggregates hinders the diffusion into the mesoporous structure, and only the external surface area can interact with the sensitizer. The mesoporous structure of TiMS could not be accessible to $\mathrm{ZnPc}$ aggregates with a consequent lower performance.

These findings suggest that mesoporous titania films could be considered the most efficient substrates for the adsorption of N719 and D5 to realize a photoanode with high efficient electronic injection.

In fact, as spectroscopic measurements showed, the N719@TiMS presents the highest UV-vis absorbance value, compared to the other $\mathrm{TiO}_{2}$ substrates, but the highest decrease in fluorescence emission intensity. These results suggest a strong interaction between the dye and the $\mathrm{TiO}_{2}$ substrate, and this condition is particularly favourable to enhance the electron injection.

\section{Acknowledgment}

This work has been supported by the Italian project EFOREnergia da Fonti Rinnovabili (Iniziativa CNR per il Mezzogiorno L. 191/2009 art. 2 comma 44).

\section{References}

[1] B. O’Regan and M. Grätzel, "A low-cost, high-efficiency solar cell based on dye-sensitized colloidal $\mathrm{TiO}_{2}$ films," Nature, vol. 353, no. 6346, pp. 737-740, 1991.

[2] M. Grätzel, "Solar energy conversion by dye-sensitized photovoltaic cells," Inorganic Chemistry, vol. 44, no. 20, pp. 6841-6851, 2005.

[3] L. M. Goncalves, V. De Zea Bermudez, H. A. Ribeiro, and A. M. Mendes, "Dye-sensitized solar cells: a safe bet for the future," Energy and Environmental Science, vol. 1, no. 6, pp. 655-667, 2008.

[4] M. K. Nazeeruddin, A. Kay, I. Rodicio et al., "Conversion of light to electricity by cis-X2bis $\left(2,2^{\prime}\right.$-bipyridyl- $4,4^{\prime}$-dicarboxylate)ruthenium(II) charge-transfer sensitizers $\left(\mathrm{X}=\mathrm{Cl}^{-}, \mathrm{Br}^{-}\right.$, $\mathrm{I}^{-}, \mathrm{CN}^{-}$, and $\left.\mathrm{SCN}^{-}\right)$on nanocrystalline $\mathrm{TiO}_{2}$ electrodes," Journal of the American Chemical Society, vol. 115, no. 14, pp. 6382-6390, 1993.

[5] L. Giribabu, K. Sudhakar, and V. Velkannan, "Phthalocyanines: potential alternative sensitizers to $\mathrm{Ru}(\mathrm{II})$ polypyridyl complexes for dye-sensitized solar cells," Current Science, vol. 102, no. 7, pp. 991-1000, 2012.

[6] A. Mishra, M. K. R. Fischer, and P. Büuerle, "Metal-free organic dyes for dye-Sensitized solar cells: from structure: property relationships to design rules," Angewandte Chemie, vol. 48, no. 14, pp. 2474-2499, 2009.

[7] G. Calogero and G. D. Marco, "Red Sicilian orange and purple eggplant fruits as natural sensitizers for dye-sensitized solar cells," Solar Energy Materials and Solar Cells, vol. 92, no. 11, pp. 1341-1346, 2008.

[8] G. Calogero, J.-H. Yum, A. Sinopoli, G. Di Marco, M. Grätzel, and M. K. Nazeeruddin, "Anthocyanins and betalains as lightharvesting pigments for dye-sensitized solar cells," Solar Energy, vol. 86, no. 5, pp. 1563-1575, 2012.

[9] E. Ronca, M. Pastore, L. Belpassi, F. Tarantelli, and F. De Angelis, "Influence of the dye molecular structure on the $\mathrm{TiO}_{2}$ conduction band in dye-sensitized solar cells: disentangling charge transfer and electrostatic effects," Energy \& Environmental Science, vol. 6, no. 1, pp. 183-193, 2013.

[10] M. K. Nazeeruddin, F. De Angelis, S. Fantacci et al., "Combined experimental and DFT-TDDFT computational study of photoelectrochemical cell ruthenium sensitizers," Journal of the American Chemical Society, vol. 127, no. 48, pp. 16835-16847, 2005.

[11] D. P. Hagberg, J.-H. Yum, H. Lee et al., "Molecular engineering of organic sensitizers for dye-sensitized solar cell applications," Journal of the American Chemical Society, vol. 130, no. 19, pp. 6259-6266, 2008. 
[12] K. Hara, T. Sato, R. Katoh et al., "Molecular design of coumarin dyes for efficient dye-sensitized solar cells," Journal of Physical Chemistry B, vol. 107, no. 2, pp. 597-606, 2003.

[13] T. Horiuchi, H. Miura, K. Sumioka, and S. Uchida, "High efficiency of dye-sensitized solar cells based on metal-free indoline dyes," Journal of the American Chemical Society, vol. 126, no. 39, pp. 12218-12219, 2004.

[14] S. Kim, J. K. Lee, S. O. Kang et al., "Molecular engineering of organic sensitizers for solar cell applications," Journal of the American Chemical Society, vol. 128, no. 51, pp. 16701-16707, 2006.

[15] D. P. Hagberg, T. Edvinsson, T. Marinado, G. Boschloo, A. Hagfeldt, and L. Sun, "A novel organic chromophore for dyesensitized nanostructured solar cells," Chemical Communications, no. 21, pp. 2245-2247, 2006.

[16] X.-F. Wang and H. Tamiaki, "Cyclic tetrapyrrole based molecules for dye-sensitized solar cells," Energy and Environmental Science, vol. 3, no. 1, pp. 94-106, 2010.

[17] F. Silvestri, M. García-Iglesias, J.-H. Yum et al., "Carboxy1,4-phenylenevinylene- and carboxy-2, 6-naphthylene-vinylene unsymmetrical substituted zinc phthalocyanines for dyesensitized solar cells," Journal of Porphyrins and Phthalocyanines, vol. 13, no. 3, pp. 369-375, 2009.

[18] G. Rossi, G. Zanotti, N. Angelini et al., "Bridged phthalocyanine systems for sensitization of nanocrystalline $\mathrm{TiO}_{2}$ films," International Journal of Photoenergy, vol. 2010, Article ID 136807, 11 pages, 2010.

[19] P. Wen, Y. Han, and W. Zhao, "Influence of $\mathrm{TiO}_{2}$ nanocrystals fabricating dye-sensitized solar cell on the absorption spectra of N719 sensitizer," International Journal of Photoenergy, vol. 2012, Article ID 906198, 7 pages, 2012.

[20] S. K. Deb, "Dye-sensitized $\mathrm{TiO}_{2}$ thin-film solar cell research at the national renewable energy laboratory (NREL)," Solar Energy Materials and Solar Cells, vol. 88, no. 1, pp. 1-10, 2005.

[21] L. De Marco, M. Manca, R. Giannuzzi, M. R. Belviso, P. D. Cozzoli, and G. Gigli, "Shape-tailored $\mathrm{TiO}_{2}$ nanocrystals with synergic peculiarities as building blocks for highly efficient multi-stack dye solar cells," Energy \& Environmental Science, no. 6, pp. 1791-1795, 2013.

[22] L. De Marco, M. Manca, R. Giannuzzi et al., "Novel preparation method of $\mathrm{TiO}_{2}$-nanorod-based photoelectrodes for dyesensitized solar cells with improved light-harvesting efficiency," Journal of Physical Chemistry C, vol. 114, no. 9, pp. 4228-4236, 2010.

[23] G. Zanotti, N. Angelini, A. M. Paoletti et al., "Synthesis of a novel unsymmetrical $\mathrm{Zn}$ (ii) phthalocyanine bearing a phenyl ethynyl moiety as sensitizer for dye-sensitized solar cells," Dalton Transactions, vol. 40, no. 1, pp. 38-40, 2011.

[24] S. Y. Choi, M. Mamak, N. Coombs, N. Chopra, and G. A. Ozin, "Thermally stable two-dimensional hexagonal mesoporous nanocrystalline anatase, meso-nc- $\mathrm{TiO}_{2}$ : bulk and crackfree thin film morphologies," Advanced Functional Materials, vol. 14, no. 4, pp. 335-344, 2004.

[25] L. De Marco, G. Di Carlo, R. Giannuzzi et al., "Highly efficient photoanodes for dye solar cells with a hierarchical mesoordered structure," Physical Chemistry Chemical Physics, vol. 15, pp. 16949-16955, 2013.

[26] S. Ito, P. Chen, P. Comte et al., "Fabrication of screen-printing pastes from $\mathrm{TiO}_{2}$ powders for dye-sensitised solar cells," Progress in Photovoltaics, vol. 15, no. 7, pp. 603-612, 2007.
[27] H. Jensen, A. Soloviev, Z. Li, and E. G. Søgaard, "XPS and FTIR investigation of the surface properties of different prepared titania nano-powders," Applied Surface Science, vol. 246, no. 1-3, pp. 239-249, 2005.

[28] T. López, J. A. Moreno, R. Gómez et al., "Characterization of iron-doped titania sol-gel materials," Journal of Materials Chemistry, vol. 12, no. 3, pp. 714-718, 2002.

[29] M. K. Nazeeruddin, R. Humphry-Baker, P. Liska, and M. Grätzel, "Investigation of sensitizer adsorption and the influence of protons on current and voltage of a dye-sensitized nanocrystalline $\mathrm{TiO}_{2}$ solar cell," Journal of Physical Chemistry $B$, vol. 107, no. 34, pp. 8981-8987, 2003.

[30] C. Pérez León, L. Kador, B. Peng, and M. Thelakkat, "Influence of the solvent on the surface-enhanced Raman spectra of Ruthenium(II) Bipyridyl complexes," Journal of Physical Chemistry B, vol. 109, no. 12, pp. 5783-5789, 2005.

[31] M. J. Root, B. P. Sullivan, T. J. Meyer, and E. Deutsch, "Thioether, thiolato, and 1,1-dithioato complexes of bis(2,2'-bipyridine)ruthenium(II) and bis(2,2'-bipyridine)osmium(II)," Inorganic Chemistry, vol. 24, no. 18, pp. 2731-2739, 1985.

[32] C. C. Leznoff and A. B. P. Lever, Eds., Phthalocyanines: Properties and Applications, vol. 1, VCH Publishers, New York, NY, USA, 1990.

[33] S. Mori, M. Nagata, Y. Nakahata et al., "Enhancement of incident photon-to-current conversion efficiency for phthalocyanine-sensitized solar cells by 3D molecular structuralization," Journal of the American Chemical Society, vol. 132, no. 12, pp. 4054-4055, 2010.

[34] L. Giribabu, C. Vijay Kumar, V. Gopal Reddy et al., "Unsymmetrical alkoxy zinc phthalocyanine for sensitization of nanocrystalline $\mathrm{TiO}_{2}$ films," Solar Energy Materials and Solar Cells, vol. 91, no. 17, pp. 1611-1617, 2007.

[35] L. Giribabu, C. V. Kumar, P. Y. Reddy, J.-H. Yum, M. Grätzel, and M. K. Nazeeruddin, "Unsymmetrical extended $\pi$-conjugated zinc phthalocyanine for sensitization of nanocrystalline $\mathrm{TiO}_{2}$ films," Journal of Chemical Sciences, vol. 121, no. 1, pp. 75-82, 2009.

[36] S. E. Koops and J. R. Durrant, "Transient emission studies of electron injection in dye sensitised solar cells," Inorganica Chimica Acta, vol. 361, no. 3, pp. 663-670, 2008.

[37] V. Biju, M. Micic, D. Hu, and H. P. Lu, "Intermittent singlemolecule interfacial electron transfer dynamics," Journal of the American Chemical Society, vol. 126, no. 30, pp. 9374-9381, 2004.

[38] M. K. Nazeeruddin, S. M. Zakeeruddin, R. Humphry-Baker et al., "Acid-base equilibria of (2,2'-bipyridyl-4,4'-dicarboxylic acid)ruthenium(II) complexes and the effect of protonation on charge-transfer sensitization of nanocrystalline titania," Inorganic Chemistry, vol. 38, no. 26, pp. 6298-6305, 1999.

[39] M. K. Nazeeruddin and K. Kalyanasundaram, "Acid-base behavior in the ground and excited states of ruthenium (II) complexes containing tetraimines or dicarboxybipyridines as protonatable ligands," Inorganic Chemistry, vol. 28, no. 23, pp. 4251-4259, 1989.

[40] M. Ziółek, X. Yang, L. Sun, and A. Douhal, "Interrogating the ultrafast dynamics of an efficient dye for sunlight conversion," Physical Chemistry Chemical Physics, vol. 12, no. 28, pp. 80988107, 2010.

[41] G. Gümrükçü, G. K. Karaoglan, A. Erdogmus, A. Gül, and U. Avciata, "A novel phthalocyanine conjugated with four salicylideneimino complexes: photophysics and fluorescence 
quenching studies," Dyes and Pigments, vol. 95, no. 2, pp. 280289, 2012.

[42] X.-F. Zhang, Q. Xi, and J. Zhao, "Fluorescent and triplet state photoactive J-type phthalocyanine nano assemblies: controlled formation and photosensitizing properties," Journal of Materials Chemistry, vol. 20, no. 32, pp. 6726-6733, 2010. 

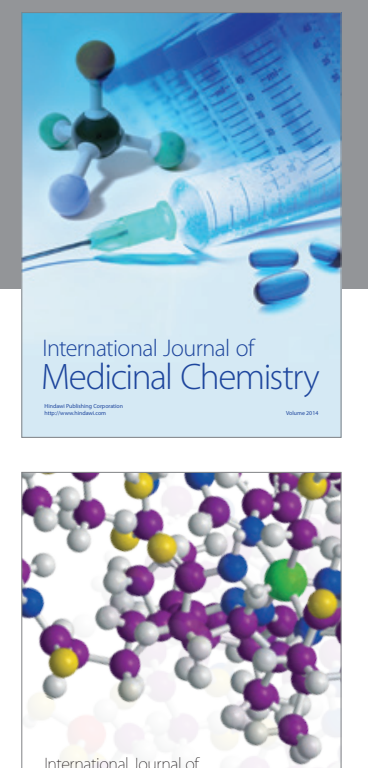

\section{Carbohydrate} Chemistry

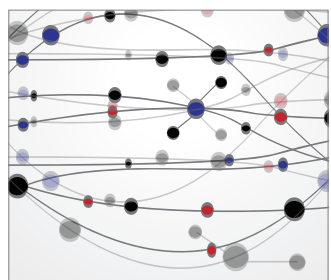

The Scientific World Journal
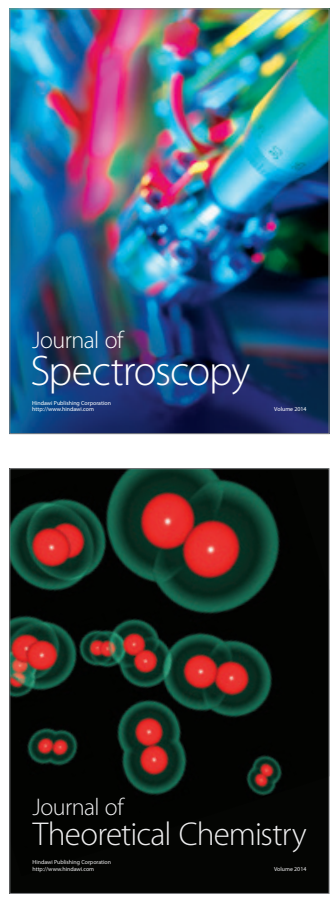
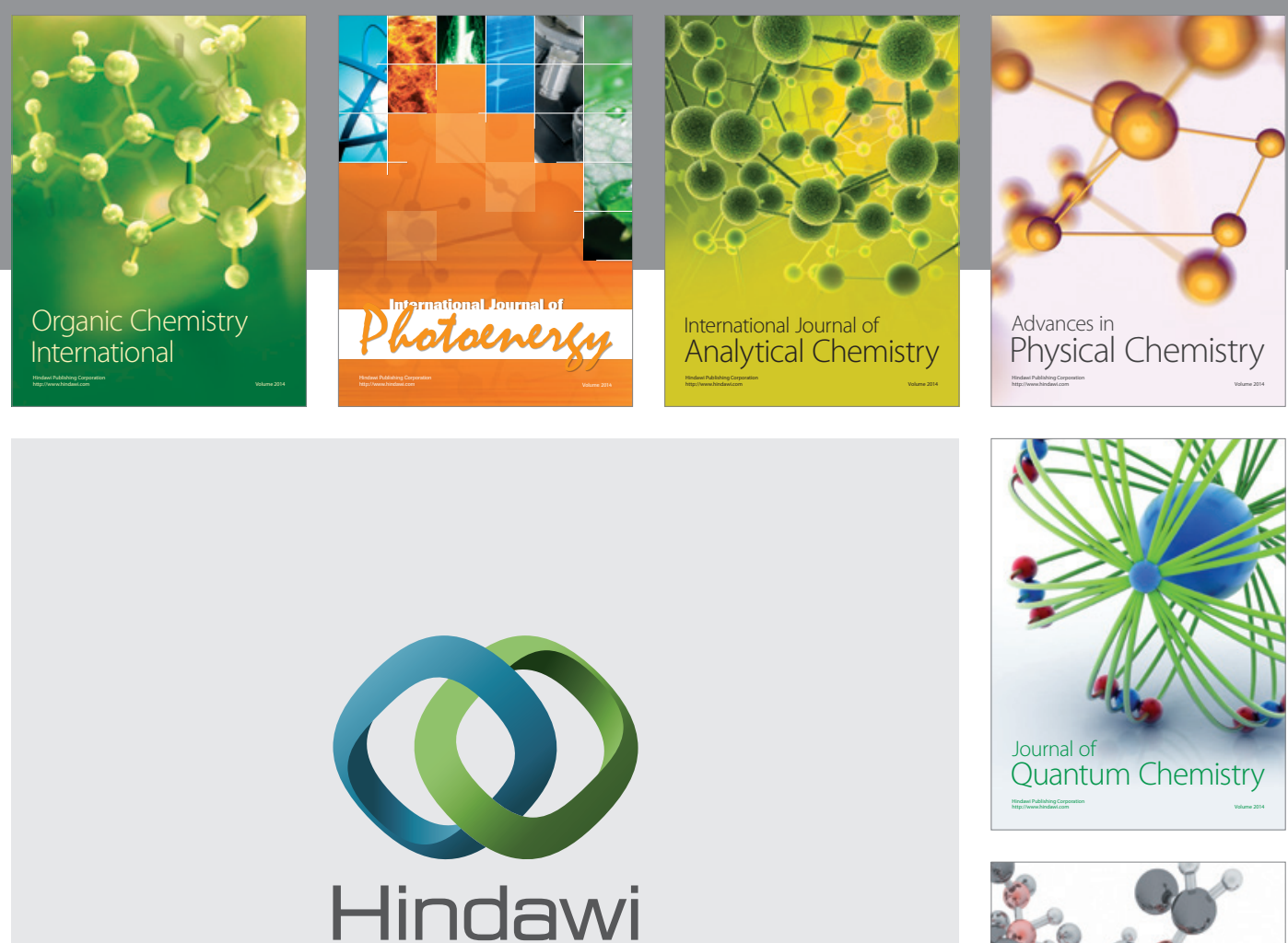

Submit your manuscripts at

http://www.hindawi.com

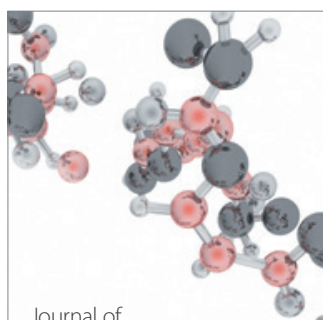

Analytical Methods

in Chemistry

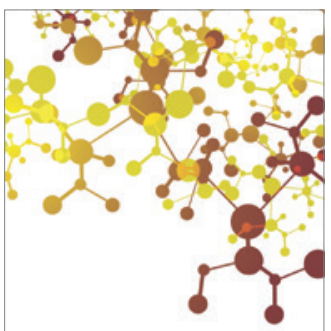

Journal of

Applied Chemistry

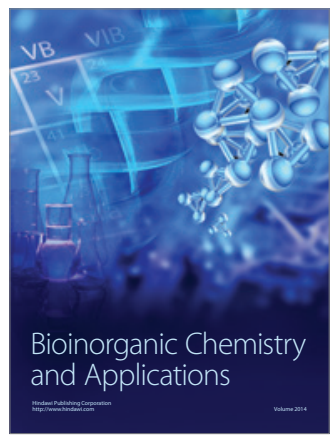

Inorganic Chemistry
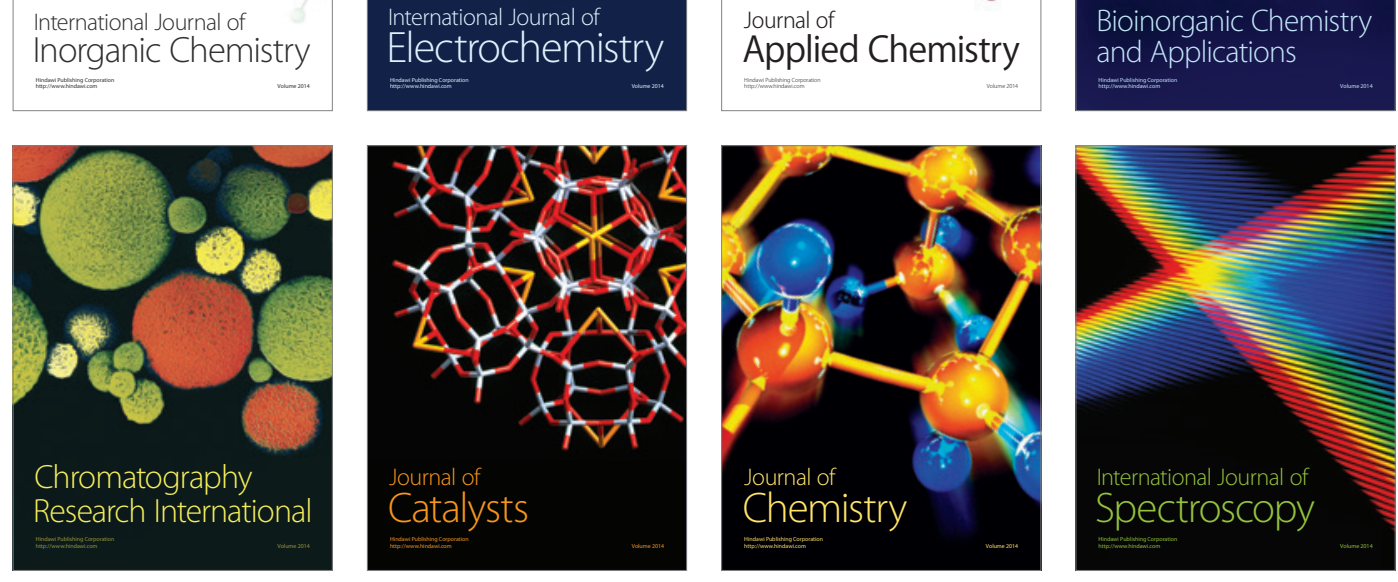